\title{
The impact of periodontal disease on the quality of life of individuals with Down syndrome
}

\section{Ana Cristina Amaral Loureiro, Fernando Oliveira Costa and José Eustáquio da Costa}

Objective: This study aimed to determine the prevalence of periodontal disease among children and adolescents with Down syndrome and the possible repercussions of such pathology in the quality of life of the group in question. Method: The sample consists of 93 individuals with Down syndrome 6 - 20 years old, living in Brazil (Minas Gerais). Periodontal probing was carried out on every site of each tooth. The Plaque Index and periodontal clinical parameters were recorded. A broad interview was carried out with the mothers, which consisted of an adaptation of the Oral Health Impact File OHIP-14 that was used to measure the negative repercussions of periodontal disease in the daily lives of these individuals. Results: The prevalence of gingivitis was $91 \%$, whereas periodontitis was found in $33 \%$ of the individuals. When the impact of periodontal disease on the quality of life was correlated with the clinical periodontal parameters, it was observed that there are significant statistical differences among them: bleeding on probing, probing depth and attachment loss. These same results, correlated with all the different groups that are categorised according to the diagnosis of periodontal disease, also show significant differences. Conclusions: Periodontal disease can be considered as a condition with high prevalence within the group in question, which has negative effects on the quality of life of the subjects. These effects are aggravated by the seriousness of the disease.

Previous studies have described a high prevalence and seriousness of periodontal disease among individuals with Down syndrome $e^{[1-4]}$. The objective of this study was to update the epidemiological profile of periodontal disease in this segment of the population and to examine the quality of life of the individuals involved.

\section{Methods}

\section{Clinical examination}

The sample of this cross-sectional study was chosen from children and adolescents supported by the PROJETO DOWN 2000, operating in the city of Juiz de Fora (Minas Gerais - Brazil). The study was focused on a group of 93 patients with the following characteristics: the patients attend the aforementioned project; their ages ranged from 6 - 20 years old, they were racially heterogeneous and socio-economically homogeneous.

The clinical examination was carried out on a dentist's chair with a reflector and the instruments used (periodontal Williams probe and buccal mirrors) were individual and autoclaved, following biosafety norms ${ }^{[5]}$. The clinical exami- nation included periodontal probing of every site of all deciduous and permanent teeth.

From the examination onwards, the periodontal clinical parameters - bleeding on probing, probing depth and attachment loss - were recorded in periodontograms, according to the model that is adopted in periodontics at the Faculty of Odontology of the Federal University of Minas Gerais, Brazil. The bleeding after probing was marked on each site, according to a dichotomous pattern: presence (+) or absence (-).

In order to evaluate the reliability of the results that were achieved, the exams were repeated in 10 patients, totalling 832 areas, so that intraexaminer agreement could be evaluated. The Kappa's agreement obtained results that were considered excellent - higher than 0.75 . In relation to the Plaque Index, an adaptation of the Turesky-Gilmore-Glickman Modification of the Quigley-Plaque Index was used ${ }^{[6]}$.

To calculate the prevalence of periodontal disease in the study group, the following diagnostic criteria were adopted:

- Gingivitis - patients who had at least one area with bleeding on probing ${ }^{[7-9]}$.
Faculty of Odontology, Federal University of Minas Gerais, Belo Horizonte, Brazil

Correspondence to Ana Cristina Amaral Loureiro $\cdot$ e-mail: anacris@powerline.com.br

doi:10.3104/reports.1998

๑) 2007 The Authors. Journal Compilation @ 2007 The Down Syndrome Educational Trust. 


\begin{tabular}{|c|c|c|c|c|c|c|c|}
\hline \multirow[b]{2}{*}{ Question } & \multicolumn{5}{|c|}{ Frequency (\%) } & \multirow[b]{2}{*}{ Mean } & \multirow[b]{2}{*}{$\mathrm{n}$} \\
\hline & 0 & 1 & 2 & 3 & 4 & & \\
\hline $\begin{array}{l}\text { 1. Have you ever noticed if your son/daughter has } \\
\text { difficulty in pronouncing any word because of } \\
\text { problems concerning the mouth, teeth or gum? }\end{array}$ & 5 & 5 & 8 & 10 & 72 & 3.7 & 92 \\
\hline $\begin{array}{l}\text { 10. Has your son/daughter ever complained about } \\
\text { bleeding gums? }\end{array}$ & 55 & 9 & 12 & 3 & 21 & 1.3 & 92 \\
\hline $\begin{array}{l}\text { 12. Have you ever noticed if your son/daughter has } \\
\text { bad breath? }\end{array}$ & 55 & 9 & 14 & 2 & 20 & 1.2 & 92 \\
\hline $\begin{array}{l}\text { 5. Has your son/daughter ever complained about } \\
\text { having red or swollen gums? }\end{array}$ & 60 & 9 & 8 & 3 & 20 & 1.1 & 91 \\
\hline $\begin{array}{l}\text { 3. Has your son/daughter ever complained about } \\
\text { pain in the mouth, gum or toothache? }\end{array}$ & 59 & 20 & 12 & 3 & 6 & 0.8 & 91 \\
\hline $\begin{array}{l}\text { 4. Has your son/daughter ever felt bothered by } \\
\text { eating a certain kind of food or does he/she stop } \\
\text { eating because of problems in the mouth, teeth } \\
\text { or gum? }\end{array}$ & 76 & 3 & 9 & 3 & 9 & 0.7 & 92 \\
\hline $\begin{array}{l}\text { 13. In general, do you think that problems in the } \\
\text { gums affect your son's/daughter's health? }\end{array}$ & 76 & 4 & 7 & 2 & 11 & 0.7 & 91 \\
\hline $\begin{array}{l}\text { 11. Has your son/daughter ever complained about } \\
\text { the sensitivity of the teeth when he or she ate } \\
\text { some thing acid or cold? }\end{array}$ & 81 & 1 & 6 & 3 & 9 & 0.6 & 91 \\
\hline $\begin{array}{l}\text { 2. Does your son/daughter complain about the } \\
\text { loss of taste of the food because of the problems } \\
\text { related to the mouth, teeth or gum? }\end{array}$ & 85 & 1 & 7 & 3 & 4 & 0.4 & 92 \\
\hline $\begin{array}{l}\text { 8. Do you think that, in any way, your son's/ } \\
\text { daughter's life was worse than it should be } \\
\text { because of the problems in the mouth, teeth or } \\
\text { gum? }\end{array}$ & 84 & 2 & 7 & 3 & 4 & 0.4 & 91 \\
\hline $\begin{array}{l}\text { 6. Have you ever seen your son/daughter irritated } \\
\text { at other people because of the problems related to } \\
\text { the mouth, teeth or gum? }\end{array}$ & 84 & 8 & 4 & 0 & 4 & 0.3 & 91 \\
\hline $\begin{array}{l}\text { 7. Have you noticed your son/daughter having } \\
\text { difficulties to fulfil obligations because of the } \\
\text { problems in the mouth, teeth or gum? }\end{array}$ & 93 & 0 & 6 & 0 & 1 & 0.2 & 90 \\
\hline $\begin{array}{l}\text { 9. Has your son/daughter ever been completely } \\
\text { unable to do any activities because of the } \\
\text { problems in the mouth, teeth or gum? }\end{array}$ & 95 & 3 & 1 & 0 & 1 & 0.1 & 92 \\
\hline $\begin{array}{l}\text { Table } 1 \text { | Decreasing order of the mean obta } \\
\text { interview. Key: 0: Never/1: Rarely/2: Occasionall } \\
\text { known }\end{array}$ & 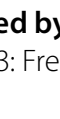 & & & & & & \\
\hline
\end{tabular}

- Periodontitis - patients that were classified as those who had slight to moderate periodontitis had at least one area with probing depth $\geq 4$ and $\leq 6 \mathrm{~mm}$ and the individuals with $>6$ $\mathrm{mm}$ were classified as having severe periodontitis $^{[10]}$.

\section{Interview with the mothers}

The objective of the interview was to evaluate the repercussions of periodontal disease on the quality of life of the patients with Down syndrome. An existing questionnaire was adapted to better examine the particular impact on this special population $^{[11,12]}$. The Oral Health Impact File OHIP-14 ${ }^{[13]}$ acted as a basic reference in this new task. In the present study, however, the questions were presented to the mothers. This modification was made to facilitate the conduct of the interview as well as to maximise the understanding of the questions. However, the son or the daugh- ter was always present during the interview and whenever possible were encouraged to answer together with the parents.

Some questions were excluded and others that were of greater interest to the investigation were added. Thus, the modifications were that the questions were addressed to the parents and the original questions 5, 6, 8, 9 and 10 were replaced by others related to periodontal health.

\section{Statistical Analysis}

In the questionnaire related to the quality of life, the results were obtained by points given to each answer. These reflect the frequency of the perception of the impact during the preceding six months. Thus, the higher the points, the higher the impact on the quality of life, i.e.:

- Never-0

- Rarely - 1

- Sometimes/Occasionally - 2

- Frequently - 3

- Always - 4

- Not Known - Excluded

The evaluation of the factors affecting the quality of life was carried out using the Kruskal-Wallis Test (3 or more samples) and the Mann-Whitney test (2 samples).

The level of significance for the evaluation of the significance of the data was $5 \%(p<0.05)$.

\section{Results}

\section{Clinical periodontal parameters}

\section{Plaque Index}

According to the methodology that was applied, the oral hygiene of $68 \%$ of the individuals could be classified as bad or extremely bad, showing severe deficiencies in the preventive practices of oral hygiene.

\section{Bleeding on probing}

This was the most prevalent variable, affecting $91 \%$ of the individuals.

\section{Probing depth}

Adopting the cut-off points previously described for the criteria of diagnosis, the results showed that $33 \%$ of the female patients had PS $\geq 4 \mathrm{~mm}$, whereas in the male group only $25 \%$ scored on this variable. The difference between the two groups was not statistically significant ( $p=0.074$ ).

\section{Attachment loss}

The results show that in $30 \%$ of the cases the level of attachment loss was in from 4 to $6 \mathrm{~mm}$ and in $10 \%$ of the cases it was $>6 \mathrm{~mm}$. 


\section{The impacts of periodontal disease on the quality of life of the study group}

The instrument that was adopted covered a range of points from 0 to 52 . The higher the points, the higher were the repercussions on the quality of life. The results varied from 0 to 40 points, with the following distribution: $36 \%$ of the patients had from 0 to 5 points, $28 \%$ from 6 to 10 points, $22 \%$ from 11 to 20 points and 14\% from 21 to 40 points. Five questionnaires that were filled in were excluded because of the number of "not known" answers (TABLE 1).

The question related to speech impairment had the highest average, that is, 3.7 points.

The second highest average was found in number 10 with 1.3 . As far as the negative impact caused by bleeding gums is concerned, the purpose was to investigate whether those with Down syndrome complained about this factor. The bleeding gum as a clinical component is easily diagnosed by periodontal probing and it is the necessary norm to treat it. The aim of the aforementioned approach was to go beyond the mere detection of this phenomenon and measure how many patients were suffering from having such a condition. This subjective component could be called the expressed or perceived necessity for treatment ${ }^{[14-16]}$

Question 12 deals with the detection of halitosis and question 5 is concerned with the redness and swelling of the gum. According to the mothers who were interviewed, $20 \%$ of them said that they "always" perceived the bad breath of their children, with a final average of 1.2. In relation to the external appearance of the gums, $20 \%$ of them said that their children were "always" complaining about the gums because they were either red or swollen.

Question 3, which was concerned with pain in the mouth, gums or teeth, had an average score of 0.8. Question 11 was concerned with the discomfort caused by radicular sensitivity and had a score of 0.6.

Questions 4 and 2, concerning eating difficulties had scores of 0.7 and $0.4^{[17]}$.

Questions 13 and 8, scoring, respectively, 0.7 and 0.4 , refer to the perception of the mothers about the quality of life of their children with Down syndrome. $76 \%$ of the mothers thought that gingival problems never affected the health of their children, in contrast to the prevalence of $33 \%$ of periodontitis and $91 \%$ of gingivitis in the group.

When asked if other people irritated their children because of problems in the mouth, gum or teeth, $84 \%$ of the mothers answered that this had never occurred.

The questions that had the lowest scores were

\begin{tabular}{|lr|}
\hline Investigated Impacts & Affected Patients (\%) \\
\hline Speech impairment & 95 \\
Discomfort caused by bleeding gums & 46 \\
Halitosis & 45 \\
Pain & 41 \\
Discomfort caused by the appearance of the gum & 40 \\
Realising that gingival problems might be affecting her son's/ & 24 \\
her daughter's health & 24 \\
Discomfort while eating & 19 \\
Radicular sensitivity & 15 \\
Loss of taste & 17 \\
Realising that her son's/daughter's life might be worse than it \\
should because of the problems in the mouth, teeth or gum \\
Irritated at other people & 17 \\
Difficulty to fulfil obligations & 7 \\
Complete inability to do activities & 5 \\
\hline
\end{tabular}

Table 2 | Percentages of the individuals who suffered, in the previous 6 months, each one of the repercussions in the questionnaire

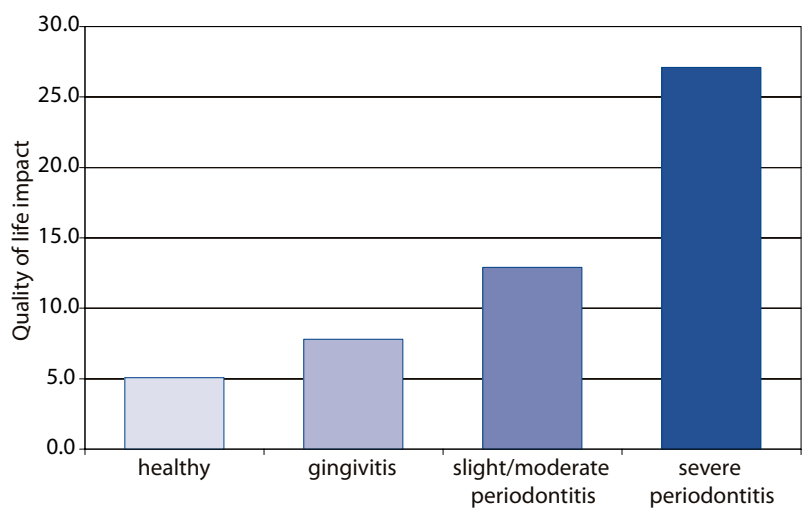

Figure 1 | Correlation between quality of life and periodontal disease.

Note: Kruskal-Wallis test - $(p<0.001)$

related to the possible difficulties of doing activities and fulfilling obligations. The averages of such questions were 0.2 and 0.1 . $95 \%$ of the mothers said that their children had never been completely unable to do tasks because of the problems that were dealt with in the interview.

The study also showed the percentages of the individuals who suffered each one of the repercussions in the questionnaire in the previous six months (TABLE 2).

The quality of life was considered worse in the group that had gingival bleeding in comparison with the group in which there was an absence of bleeding on probing.

A similar correlation was established between the quality of life and the probing depths $(p<$ 0.001). 
The group whose values were higher than $3 \mathrm{~mm}$ in the variable of the attachment loss showed greater negative repercussions in the quality of life $(p<0.001)$.

The main point of this analysis was the hypothesis that periodontal disease was capable of generating negative effects on the quality of life of the individuals involved in the study.

In order to verify this possibility, the results of the quality of life were correlated with the groups that were categorised by the type of periodontal disease, namely: slight to moderate periodontitis and severe periodontitis.

The results that were obtained suggest that periodontal pathology was able to affect the health of its subjects, in a way that was statistically significant in all of the groups $(p<0.001)$.

It is also worth mentioning that these negative impacts were more severe in proportion to the increase of the seriousness of the disease and that the difference was not only among the healthy and non-healthy groups, but also among the groups of patients that have gingivitis and periodontitis and among the groups of patients that have the two forms of periodontitis, which is also shown in FIGURE 1.

\section{Discussion}

Initially, the evaluation, in a highly critical perspective, should be focused on the fact that the question related to speech impairment had the highest average score. After all, phonation disturbances are extremely common among people with Down syndrome ${ }^{[18]}$.

Another important issue refers to the contrast of the results. Several previous studies detected that the acts of mastication and deglutition were among those that were the most affected by alterations of oral health ${ }^{[17,19-23]}$. It is highly probable that the discrepancy between the results is caused by the fact that the subjects of the other studies were much older, being a group of old people, partially or totally toothless.

In the present study, $40 \%$ felt discomfort about the gingival aspect. The importance given to the appearance of the teeth and gums seems to be intimately related to the individual and subjective concept of aesthetics and also to the selfexamination of oral health ${ }^{[24]}$. Therefore, with regard to the patients that have Down syndrome, the result concerning the discomfort caused by the red and oedematous aspect of the gum can be considered high.

A plausible hypothesis might be that the result actually reflects the expectations of the mother in relation to the son's/daughter's appearance. After all, it is well known that there are methodological problems in the investigation of the reports of oral health among children, because the parents usually act as the "reporters" and what they state might not fully correspond to what is actually felt by their sons/daughters ${ }^{[25]}$.

It is also worth mentioning that if the subjective data is compared to the objective data in relation to the bleeding gums, it is possible to observe that, in this study, there is an agreement between the results that were obtained by the clinical examination and the ones based on subjective evidence.

In relation to the repercussions of periodontal disease in the quality of life of the group in question, the results show a significant correlation among all the clinical periodontal parameters and the scores obtained by the instrument that was used. It is possible to observe that clinical periodontal alterations, verified through the bleeding on probing, probing depth and attachment loss, are therefore, able to cause negative impacts in the daily lives of these individuals.

The correlation between these results and the group categorised by the diagnosis of periodontal disease show that periodontal disease was really able to cause negative consequences for the quality of life of the individuals involved in this research. This correlation was also significant among the groups that were subdivided according to the seriousness of the disease, showing that the negative reflections discussed in this study were higher in proportion to the aggravation of periodontal disease.

The results achieved in this study, associated with the review of the scientific literature, show that there is a problem in the preventive odontological programs that deal with this special segment of the population, making it necessary to take effective measures to carry out early periodontal monitoring in children and adolescents that have this syndrome. 
1. Johnson NP, Young A. Periodontal disease in Mongols. Journal of Periodontology. 1963;34: 41-47.

2. Brown RH. A longitudinal study of periodontal disease in Down's syndrome. New Zealand Dental Journal. 1978;74:137-144.

3. Reuland-Bosma W, Van Dijk J. Periodontal Disease in Down's Syndrome: a review. Journal of Clinical Periodontology. 1986;13:64-73.

4. Modéer T, Barr M and Dahllof G. Periodontal bone loss in children with Down's syndrome. Scandinavian Journal of Dental Research. 1990; 98:228-234.

5. Cotone JA, Therazalmy GT, Mollinari JA. Practical infection control dentistry. Philadelphia: Lea and Febiger; 1991.

6. Carranza JFA, Newman MG. Periodontia Clínica. Rio de Janeiro: Guanabara Koogan; 1997.

7. Greenstein G, Caton J, Polson AM. Histological characteristics associated with bleeding after probing and visual signs of inflammation. Journal of Periodontology. 1981;52:420-425.

8. Ciancio SG. Current status of indices of gingivitis. Journal of Clinical Periodontology. 1986;13: 375-378.

9. Lang NP, Adler R, Joss A, Nyman S. Absence of bleeding on probing: an indicator of periodontal stability. Journal of Clinical Peridontology, Copenhagen. 1990;17:714-721.

10. American Academy of Periodontology. Parameters of care. Journal of Periodontology. 2000;71 (Supplement).
11. Locker D, Allen PF. Developing short-form measures of oral health-related quality of life. Journal of Public Health Dentistry. 2002;62:13-20.

12. Weintraub JA. Uses of oral health related quality of life measures in public health. Community Dental and Oral Epidemiology. 1998;15:8-12.

13. Slade GD. Derivation and validation of a shortform oral health impact profile. Community Dental and Oral Epidemiology. 1997;25:284-90.

14. Leão AT, Sheiham A. The development of a socio-dental measure of dental impacts on daily living. Community Dental Health. 1996;13:22-26.

15. Hayes $C$. The use of patient based outcome measures in clinical decision making. Community Dental and Oral Epidemiology. 1998;15:19-21.

16. Sheiham A. Determinação das necessidades de tratamento odontológico: uma a bordagem social. In Pinto VG. Saúde bucal coletiva, São Paulo: Ed. Santos;2000:p.223-250.

17. Reisine ST, Fertig J, Weber J, Leder S. Impact of dental conditions on patient's quality of life. Community Dental and Oral Epidemiology. 1989; 17:7-10.

18. Burns GW. Genética: uma introdução à hereditariedade. 5th edn. Rio de Janeiro: Guanabara; 1984.

19. Atchinson KA, Dolan TA. Development of the geriatric oral health assessment index. Journal of Dental Education. 1990;54:680-687.

20. Locker D, Miller Y. Subjectively reported oral health status in an adult population. Community Dental and Oral Epidemiology. 1994;22:425-430.
21. Adulyanon S, Vourapukjaru J, Sheiham A. Oral impacts affecting daily performances in a low dental disease. Community Dental and Oral Epidemiology. 1996;24:385-9.

22. Tsakos G, Marcenes W, Sheiham A. Cross-cultural differences in oral impacts on daily living between Greek and British older adults. Community Dental Health. 2001;18:209-213.

23. Chavers LS, Gilbert GH, Shelton BJ. Two-year of oral disadvantage, measure of oral healthrelated quality of life. Community Dental and Oral Epidemiology. 2003;31:21-29.

24. Ostberg AL, Halling A, Lindblad U. A gender of self perceived oral health in adolescents: associations with attitudes and behaviours. Community Dental and Oral Epidemiology. 2000; 18:110-116.

25. Jokovic A, Locker D, Stephens M, Kenny D, Tompson B, Guyatt G. Validity and reliability of a questionnaire for measuring child oral-healthrelated quality of life. Journal of Dental Research. 2002;81:459-463.

Received: 31 October 2005; Accepted 14 August 2006; Published online: 30 July 2007. 